\title{
Digital Literacy: A Vital Competence for 2010?
}

\author{
Denise Leahy and Dudley Dolan \\ School of Computer Science and Statistics, \\ Trinity College, \\ Dublin 2, Ireland \\ \{denise.leahy, dudley.dolan\}@cs.tcd.ie
}

\begin{abstract}
People are living in a fast changing world today in both their business and personal lives. With the rate of change in technology continuing at Gordon Moore's 1965 predictions [1], what competencies are needed to take full advantage of today's Knowledge Society? The EU has recognised the need for digital literacy and has included this in the definition of eInclusion [2]. This paper defines digital literacy as a competence which is vital for all citizens, examines the changing definitions of digital literacy, looks at what the certification bodies are saying and proposes the competencies which are required and which define digital literacy today.
\end{abstract}

Keywords: Digital literacy, competencies, eInclusion.

\section{Introduction}

In this, the second decade of the $21^{\text {st }}$ century, a Knowledge Society exists from which we all should benefit. However, some people are excluded; often caused by social, economic or accessibility issues. And even if technology is available, a person will still be excluded if he or she cannot use the technology or cannot use it efficiently and safely. It is vital that these issues are addressed by governments worldwide. The European Union has recognised the need for digital literacy and has included this in their definition of eInclusion [2] - "To participate and take advantage (of the Information Society), citizens must be digitally literate - equipped with the skills to benefit from and participate in the Information Society".

Tim Berners-Lee thought of the Web as a "common information space in which we communicate by sharing information" [3]. This is already happening - the use of social networking is growing " 41.7 million Europeans are regular users of social networking sites. They will be 107.4 million by the end of 2012. Europeans are using them to share personal and professional experiences, keep in contact with family and friends, and organise their social lives." [4] However, for many people the computer is not a natural tool, even causing fear of doing something wrong, of "breaking the machine", of getting lost online, etc. Such people need guidance on what is required to help them use technology, remain safe online and become confident members of the Knowledge Society. A definition of the competencies and skills is needed.

There are different levels of digital literacy competence and, with the rapid advances in technology, what is required to be digitally literate changes continually. The 
skills required to complete a task can change with different versions of software, hardware or communications technology. What was difficult to do 20 years ago can be performed with the push of a button today. Yet, because the functionality is growing, more is expected of a digitally literate person.

This paper argues that, even with the availability of technology, without digital literacy a person cannot take full advantage of the Knowledge Society. It examines the changing definitions of digital literacy and proposes the competencies which are required and which define digital literacy today.

\section{The Changing Perception of Digital Literacy}

Before the 1960s, computers were mostly used in scientific laboratories or academic environments. Although there were some business machines, for example Leo, Univac, and DEC, these were not in general use in business. In 1959, IBM launched its 1400 series of business computers and a high level programming language (COBOL) was created. In 1959, a conference was held in Paris as a result of which the International Federation for Information Processing (IFIP) was founded in 1960 [5]. During the '60s there was wider use of computers in business. These computers were big machines, taking up much space and were usually operated and programmed by computer professionals. Many of these machines ran corporate systems with only cards or paper tape as input and hard copy printouts as output. The business functions running these machines and providing the services were often called Data Processing (DP) departments. At that time, to be "computer literate" meant that you were a DP professional. In the '70s the use of computers spread in business with mid-range computers such as Digital Equipment Corporation (DEC) and Data General (DG) equipment becoming common. There have been many definitions of digital literacy since these early days of computing. The term "computer literacy" appeared in writings in the 70s [6].

As computers began to be used widely in business, it was necessary for the business user to become competent in using computer systems related to their specific task or job. Business people began to use query languages and CASE tools (Computer Aided Software Engineering). However the programmer was still the professional expert and the business user had limited tools. End user tools became available during the late '70s. These tools gave the user the ability to manipulate their data and, with the advent of macros, the user could write a small amount of code. End user systems development arrived when personal computing tools allowed users to develop small systems - word processing, spreadsheets and small databases were available to all. The term "computer literacy" at this time included the use of personal computers by the non technical person. However the meaning was not entirely clear - as Van Dyke [7] stated in 1983 "if the vernacular of the term computer literacy is assured, its meaning is not". During the 90s, the term "digital literacy" began to appear.

Paul Gilster, in 1997, suggested that to be digitally literate a person should be able to find information on line and evaluate it, suggesting that the skills of such a person should include the use of email and search engines and the ability to evaluate a Web Site, other on line resources and other information resources [8]. According to Wilhelm in Digital Nation [9], to be digitally literate you should be able to "Access, manage, integrate, evaluate and create information". 
The term "digital literacy" developed to include media literacy and the ability to interpret information. Eshet-Alakali et al suggest that "Having digital literacy requires more than just the ability to use software or to operate a digital device; it includes a large variety of complex skills such as cognitive, motoric, sociological, and emotional that users need to have in order to use digital environments effectively." [9]

The definitions, therefore, have included:

- Digital literacy - this term is used today, but it has different meanings. It can include all of the terms below

- Computer literacy - started off with the DP people, the technical people who were computer professionals

- Information literacy - this definition usually means digital literacy and includes the ability to verify, interpret and validate the information

- Cyber literacy - sometimes used to include competence with using the Internet, communications and the Web

The definition used by the European Union is "Digital literacy involves the confident and critical use of Information Society Technology (IST) for work, leisure and communication. It is underpinned by basic skills in ICT: the use of computers to retrieve, assess, store, produce, present and exchange information, and to communicate and participate in collaborative networks via the Internet."

\section{Digital Literacy Today}

Technology is becoming part of everyday life today. We talk to our distant friends using technology, sending photos, family information and chat. Businesses are using technology to communicate with customers and suppliers; governments are communicating with citizens using technology. Digital literacy is necessary take full benefit of all the Knowledge Society can offer. According to the Danish Technological Institute [10] "Digital literacy is needed by all citizens, for example in order to:

- $\quad$ ensure better service access and use

- $\quad$ ease citizens' daily life burdens (such as engaging with public administrations)

- $\quad$ obtain better access to education, training, work, and jobs

- $\quad$ improve each citizen's personal capacity (quality of life and life chances)

- enhance citizens' social networks and participation."

The term "digital literacy" is used by the European Union in "Digital Literacy: Skills for the Information Society", saying that "Information and communications technologies (ICTs) affect our lives every day - from interacting with our governments to working from home, from keeping in touch with our friends to accessing healthcare and education".

In this paper, digital literacy is used to refer to the use of electronic equipment by all members of society, for personal and social interactions and for educational and business needs. The definition includes the ability to use technology, including a computer and mobile devices, to send e-mail, to use common household equipment, to locate and understand information on the web and to use other personal computer 
based tools. Microsoft defines their digital literacy curriculum as having the objective of - "The goal of Digital Literacy is to teach and assess basic computer concepts and skills so that people can use computer technology in everyday life to develop new social and economic opportunities for themselves, their families, and their communities." (http://www.microsoft.com).

\section{Why Are the Competencies Required?}

So much data is available on line that it is necessary to be able to discern the accuracy and integrity of such data - "IT literacy..... must also capture the notion of information literacy - the ability to assess the validity of various sources of information" [11]. We need to understand where the data comes from and which information is valid from the huge amount currently available - "If we are to be drinking from a firehose, with billions of web pages at our fingertips, then we should possess the skills to manage its flow" according to Wilhelm [12].

People need to be aware of privacy and security issues when they are using technology. Using the Internet often involves entering personal details on a web page. It is important that people know how to work safely on line. Wilhelm suggests that "we are finding ourselves at the new frontier of civil rights".

People could be socially excluded with the disappearing of local shops and services. In the United Kingdom, as in many other countries, there has been a reduction of $21 \%$ in the number of bank branches during the last decade [13]. Use of technology to provide services and communication capability will be necessary to maintain the quality of life. Knowing how to use technology can help reduce social exclusion. "Indicators of social exclusion can be income-related but also extend to areas such as social contact and support, good health and a feeling of participation and being heard" [14]. This exclusion could extend to government services and even the move to e-Democracy. Governments are increasing their on line services and their communications with their citizens - this is "eGovernment" today. Rheingold spoke of a "Citizen based democracy" [15] and people who do not have access to the Internet will be at serious disadvantage. In business, the use of technology to communicate with business partners, customers, employees and potential employees is growing, especially the use of social networking. Job advertisements are often placed on line and cvs can be uploaded.

User generated content (or user created content) is created every day. People communicate on Twitter, some news agencies get news faster through this. When something happens today, it is usually possible to find a video on "YouTube" within minutes. Shortly after Susan Boyle sang on the UK's "Britain's Got Talent", it was seen by millions of people [16]. As of January 2010, this specific video had $86,315,736$ views and there are many more YouTube copies of this performance. In Dublin, during a very cold period in January 2010 a news item on the national TV station showed a man falling over on the ice - this was the most watched video on YouTube that week [17]. Video can be distributed immediately to a potential viewing audience of 100 million people [18].

Are older people excluded from this Knowledge Society? The European Commission believes they should benefit from technology. According to Frans de Bruïne, 
(Director, European Commission), "By 2013, the Commission plans to invest one billion Euro in researching and piloting digital technologies that make the lives of older citizens easier" - it is possible that these initiatives could "turn the silver challenge into a golden opportunity" [19]. Research in the EU "The 2009 Ageing report" shows the number of older people in the EU will grow between 2008 and 2060, while the number of young people will decline gradually [20]. This report projects that in seven of the member states (Belgium, Ireland, France, Cyprus, Luxembourg, Sweden and the UK) the working population will grow slightly, but that this population will drop in the other 20 states. The number of elderly people will almost double, rising from 85 million in 2008 to 151 million in 2060 in the EU and the number of people over 80 years of age is projected to triple by 2060 [21]. Older people must be included.

A person with a disability can benefit from technology and will usually use assistive technology in the form of hardware or software. This involves further competence requirements for both the user and the designer. The person with the disability will need to know how to use the assistive technology and the designer of a web site will need to understand how such technology works in order to make the web site accessible [22].

Access to education can be enhanced by eLearning and digital literacy is needed to get the best from eLearning tools. According to the EU, "Digital competence" is one of the eight key competences for Life Long learning [23].

\section{What Are the Certification Bodies Saying about Competencies?}

There are many definitions of digital literacy. According to Wikipedia "Digital literacy is the ability to locate, organize, understand, evaluate, and create information using digital technology". There are also recognized certification bodies that have their own, similar definitions. This section looks at three of the current certifications and compares their definitions of digital literacy. These bodies are ECDL/ICDL, Microsoft and IC3. A project recently initiated by CEN to examine the requirements for an End User eSkills Framework could also contribute to the harmonization of certifications through its proposed linkage to the European Qualification Framework (EQF).

\subsection{ECDL/ICDL}

ECDL was set up in 1997 as an initiative of the Council of European Professional Informatics Societies (CEPIS). It is an international organization, run by the ECDL Foundation [24]. ECDL is operating in over 120 countries and, outside Europe, it is known as the International Computer Driving License (ICDL). ECDL consists of many programmes, but the core ECDL programme is accepted by many organizations as a definition of digital literacy and there were almost 10 million people registered by the end of 2009 [25].

This core programme consists of 7 modules as follows:

- Module 1 - Concepts of Information and Communication Technology (ICT)

- Module 2 - Using the Computer and Managing Files

- Module 3 - Word Processing 
- Module 4 - Spreadsheets

- Module 5 - Using Databases

- Module 6 - Presentation

- Module 7 - Web Browsing and Communication

The core programme is recognized as a definition of digital literacy for the workplace and there are two other programmes requiring a lower level of skill. These are EqualSkills and eCitizen. EqualSkills consists of Desktop Computing skills for the complete beginner and includes the basic skills necessary to use the Internet and e-mail, to turn on the computer and understand the basic component parts of a computer, to use the keyboard and the mouse and work with a modern desktop and to use a text editor to create, save and print a simple document. The e-Citizen is at a more advanced level and is designed to help the citizen work effectively in the e-world. It consists of three blocks - the Foundation Skills, the Information Search and The e-Participation Block

ECDL also provides advanced programmes:

- ECDL / ICDL Advanced Word Processing

- ECDL / ICDL Advanced Spreadsheets

- ECDL / ICDL Advanced Database

- ECDL / ICDL Advanced Presentation

- ECDL / ICDL CAD

And professional programmes:

- ECDL / ICDL WebStarter

- ECDL / ICDL ImageMaker

- ECDL / ICDL Health

\subsection{Microsoft}

The Microsoft Digital Literacy curriculum has five parts:-

- Computer Basics - consists of the fundamentals of computing, the components of a computer and the basics of operating system, and the use of a mouse and a keyboard

- The Internet and the World Wide Web - shows how to connect to the Internet, browse Web pages, navigate Web sites, use search engines, and send and receive e-mail

- Productivity Programs - explores the most common productivity software applications used in business, in education, and at home, consisting of the basics of word processing, spreadsheets, presentation software, and databases

- Computer Security and Privacy - explains the risks and threats to computer security and privacy

- Digital Lifestyles - introduction to the new digital technologies, including digital audio, digital video, and digital photography

Microsoft also provides certification at a professional level and includes the Microsoft Certified Application Specialist (MCAS) and the Microsoft Office Specialist (MOS). As specified on the Microsoft website: 
"The Microsoft Certified Application Specialist (MCAS) credential validates skills in using the 2007 Microsoft Office system and the Windows Vista operating system, meeting the demand for the most up-to-date skills on the latest Microsoft technologies. Candidates who successfully complete the program by passing a certification exam show that they can meet globally recognized performance standards. Candidates must pass one certification exam in order to earn the MCAS credential.

The Microsoft Office Specialist (MOS) program offers certification tracks for Office 2003, Office XP, and Office 2000. To earn an MOS certification for Microsoft Office, you must pass one or more certification exams. MOS certification exams provide a valid and reliable measure of technical proficiency and expertise by evaluating your overall comprehension of Microsoft Office or Office Project programs, your ability to use advanced features, and your ability to integrate Office programs with other software." [26]

\subsection{IC3}

The Global Digital Literacy Council (GDLC) established the curriculum for Certiport Internet and Core Computing Certification. The latest standard, Global Standard 3, was signed by the council on August 1, 2008. According to the GDLC Web site, "The development of the Global Standard 3 took over 9 months of research, data collection from $400+$ subject matter experts from over 30 countries and final ratification from the members of the Global Digital Literacy Council." [27]

The $\mathrm{IC}^{3}$ Global Standard 3 consists of three parts:

\section{Computing Fundamentals}

- Computer Hardware, Peripherals and Troubleshooting - this part includes understanding the standard hardware that is used today, including input and output devices,. It also includes how to solve problems hardware problems.

- Computer Software - examines how software and hardware work together to perform computing tasks, looks at how software is developed and upgraded including standard software such as word processing, spreadsheets, presentation software, databases, graphic and multimedia programs, etc

- Using an Operating System - this examines how and operating systems works, its, functions and how to manage them. It looks at how to manipulate windows, folders, files and shortcuts; install, uninstall and run applications; and solve common problems

\section{Key Applications}

- This consists of being able to start and end an application successfully and includes being able to use the functionality of word processing, spreadsheets and presentation software.

\section{Living Online}

- This part includes the fundamentals of networking and the benefits and risks of network computing; the different types of electronic communication/collaboration and how they work, including email. 
- Using the Internet and the World Wide Web, includes learning how to evaluate the quality of information found on the Web and how to browse and use websites.

- The Impact of Computing and the Internet on Society - identifies how computers are used in different areas of life, the risks of using computer hardware and software, and how to use computers and the Internet safely, ethically and legally.

\subsection{What Have They in Common?}

ECDL and IC3 claim to be vendor independent while Microsoft is obviously linked to Microsoft products. All three claim to have been informed by subject matter experts with a strict development process and quality assurance. Microsoft and ECDL define very basic levels of digital literacy, designed for people who want to use computing for email and simple tasks using the World Wide Web. All three programmes have a professional level of certification with are accepted by employers and some educational organizations as professional digital literacy.

At a very basic level of digital literacy they all identify that using email, searching the Web using a browser and using a text editor or word processor are the simple competence requirements. The next level includes the competence to discern the validity of information found online, the basics of computer technology ant the use of other personal productivity tools, such as spreadsheets.

\subsection{A Framework}

The definition of digital literacy is changing. Would a framework to identify these changing skills be of use? To address this, the European Union CEN/ISSS Workshop on ICT Skills has commissioned an End User e-Skills Framework Requirements project $^{1}$ to identify the requirements for such a framework. This project is surveying companies in industry, certifying organisations, regulatory authorities and individuals. The project plans to define what is required of end user e-Skills, to make proposals for developing such a reference framework and to outline tools that could benefit framework users.

\section{What Are the Competencies Required in Today's Knowledge Society}

\subsection{The Core of Digital Literacy}

In 1983, Spresser argued that "definitions of computer literacy abound" [28], but suggests that a knowledge of computers and how they work is a necessary part of this literacy, coupled with the ability to use the available software. More than twenty years later, Mason et al [29] believe that computer (digital) literacy consists of "awareness" and "competence". This section describes the basic competencies required for living

\footnotetext{
${ }^{1}$ http://www.ecompetences.eu/site/objects/download/ 5101_EndUsereSkillsFrameworkRequirementsOverview.pdf
} 
in and taking advantage of the opportunities offered by today's Knowledge Society. These are split into two parts - first the competencies required to be part of this society are listed, followed by a definition of what are, arguably, part of the digital literacy competencies required to exploit the technology.

\section{Critical}

- Basic knowledge of technology and basic skills

- The ability to search for and locate information

- The ability to identify the valid information

- The ability to connect to a network

- The ability to know when there is a problem

- The skill to use a computer safely, this skill involves knowledge of the basics of hardware and software

- The ability to send an email, receive an email, reply to an email and work with attachments

- Knowing how to communicate using a mobile telephone

- Knowing how to create, read and respond to texts on a mobile telephone

- The ability to use Mp3 players or iPods (and iPads)

- Vital for persons with a disability is the knowledge and skills required to use assistive technology

\section{Other basic competencies}

- Knowledge of the risks of misusing information

- Understanding security and ethics in using technology

- Having technical awareness and understanding that technology changes e.g. current opportunities with Web 2.0, Mobile devices, etc

- Ability to access and use learning resources on computers

- Findings things using mobile telephones

- Using the computer to communicate with friends

- Using the computer to post pictures or information

- Sharing and exchanging ideas with friends and family members

- Identifying new uses for technology at home

- Accessing, copying, manipulating and playing music and videos

- Awareness of assistive technology

\subsection{Digital Literacy at Work}

The previous sections described the basic digital literacy competencies needed in everyday life. This section looks at digital literacy for work and education.

At work - In most cases a business person will need the basic digital literacy competencies defined above and will also need other job-specific competencies and organisational systems. Such specific work-related systems may be in manufacturing (Computer Aided Manufacturing or Computer Aided Design), finance (use of accounting systems), legal, etc For employment generally, there is a need for an understanding of the corporate or organisational "acceptable use" of technology, to have the ability to work in remote teams and to be conscious of Web 2.0 and on-going technological advances. 
Teaching and Education - Jans et al [30] believe that teachers need more than just technical skills. "Teaching and learning with ICT requires specific competencies for teachers and lecturers." They identify that teachers need to be able to use a Virtual Learning Environment and understand the implications of this, including course design and education delivery using these methods. Students need to be familiar with the use of search engines to aid their research and they also need to be able to navigate Learning Management Systems (LMS) which are used in many second and third level colleges as a teaching resource.

Research - The ability to use technology as a huge source of information has changed the efforts involved in research, especially the search for previously published literature and findings. However, the ability to discern the validity of such information is vital.

Digitally literacy for the IT professional - The CEN Workshop on ICT Skills has defined a European framework for ICT Professionals ${ }^{2}$. This consists of a framework and a guide to implementing the framework. There are 5 high level competences with 32 competences defined at the lowest level. The framework was designed to match the requirements for IT professionals in all industry sectors.

Technical and designers - Digital literacy is necessary for the designers of web sites. While this is more difficult with user generated content, it is vital that accessibility is built into web sites to ensure eInclusion. Designers need to have the ability to design digital information and the ability to present digital information in a usable and format.

\section{Conclusions}

The definition of digital literacy has changed over the years, from the early days of computing when to be "computer literate" meant you were a computer professional to the new and evolving meaning of the term. This paper argues that to be digitally literate is vital in 2010. The specific competencies which make up digital literacy can vary and will change, but the basic or core competencies can be defined today. Other digital competencies can be defined for opportunities in education, business and specific jobs.

As digital literacy needs continue to evolve and new technology emerges, the challenge will be to ensure that the population at large can attain and maintain a reasonable level of competence to benefit from the Knowledge Society.

\section{References}

1. Moore, G.: Moore's Law (1965), http://www.intel.com/technology/ mooreslaw/ (accessed February 1, 2010)

2. Digital Literacy: Skills for the Information Society, http://ec.europa.eu/ information_society/tl/edutra/skills/index_en.htm (accessed January 31,2010 )

\footnotetext{
${ }^{2}$ http://www.ecompetences.eu/
} 
3. Berners-Lee, T.: The World Wide Web: A Very Short Personal History (1998), http: //www.w3 .org/People/Berners-Lee/ShortHistory.html (accessed February 19, 2009)

4. e-Inclusion: Be Part of It! http://ec.europa.eu/information_ society/activities/einclusion/bepartofit/index_en.htm (accessed January 30, 2010)

5. Computer history, http://www. computerhope.com/history/196080.htm (accessed January 25, 2010)

6. Gupta, G.K.: Computer literacy: essential in today's computer-centric world. SIGCSE Bull. 38, 115-119 (2006)

7. Van Dyke, C.: Taking “computer literacy” literally. Communications of the ACM 30, 366374 (1987)

8. Gilster, P.: Digital literacy. John Wiley, Chichester (1997), ISBN 0471165204

9. Eshet-Alakali, Y., Amichai-Hamburger, Y.: Experiments in Digital Literacy. CyberPsychology and Behavior 7, 421-429 (2004)

10. Supporting Digital Literacy, http://www.digital-literacy.eu/ (accessed February 1,2010 )

11. Perez, J., Meg Murray, M.: Computing for the masses: extending the computer science curriculum with information technology literacy. Consortium for Computing Sciences in Colleges 24, 220-226 (2008)

12. Wilhelm, A.G.: Digital nation: toward an inclusive information society. MIT Press, Cambridge (2004)

13. Working Group on Ageing Populations and Sustainability, http://europa.eu/epc/working_groups/ageing_en.htm

14. Waterhouse, C., Angley, P.: Social exclusion among older people, a preliminary study from inner-city Melbourne (2005), http://www.bsl.org.au/pdfs/ Social_exclusion_older_people.pdf (accessed February 1, 2010)

15. Rheingold: In: Hand, M. (ed.) Making digital cultures: access, interactivity, and authenticity, Aldershot, Ashgate (2008)

16. Britain's got talent, http://www.youtube.com/watch?v=91p0IWv8QZY (accessed January 25, 2010)

17. Falling over on the ice, http: / /www . youtube. com/watch?v=7CT0a-Hgumo (accessed January 25, 2010)

18. YouTube Surpasses 100 Million US Viewers for the First Time, http: / /www.comscore.com/Press_Events/Press_Releases/2009/3/Y ouTube_Surpasses_100_Million_US_Viewers (accessed February 12, 2010)

19. Turning the silver challenge into a golden opportunity, http://sap. info/archive/ interviews/int_Interviews_Turning_the_Silver_Challenge_into _a_Golden_Opportunity_01.08.2007.html (accessed February 2010)

20. Age Concern and Help the Aged proposals for Budget 2009 (2009), http: / / www . ageconcern. org. uk (accessed February 12, 2010)

21. The 2009 Ageing Report (2009), http://ec.europa.eu/economy_finance/ publications/publication13782_en.pdf

22. AbilityNet: State of the eNation Reports: Social Networking Sites Lock Out Disabled Users (2008), http: / / www . abilitynet.org.uk/enation85 (accessed January 19, 2010)

23. Commission of the European Communities, Proposal for a recommendation of the European Parliament and of the Council on key competences for lifelong learning (2005), http: / / ec.europa.eu/education/policies/2010/doc/keyrec_en.pdf (accessed February 12, 2010) 
24. Carpenter, D., Dolan, D., Leahy, D., Sherwood-Smith, M.: ECDL/ICDL: a global computer literacy initiative. In: 16th IFIP Congress, ICEUT200, Educational uses of Information and Communication Technologies, Beijing, China (2000)

25. ECDL, http://www. ecdl.org

26. Microsoft, http://www.microsoft.com

27. IC3, http://www. certiport.com/portal/DesktopDefault.aspx

28. Spresser, D.: A Moderate approach to Computer Literacy. Communications of the ACM (1985)

29. Mason, J., McMorrow, R.: YACLD (yet another computer literacy definition). Published by the Consortium for Computing Sciences in College (2006)

30. Jans, Sebastiaan, Awouters: Valère E-learning Competencies for Teachers in Secondary and Higher Education. International Journal of Emerging Technologies in Learning (iJET) 4(2) (2009) 